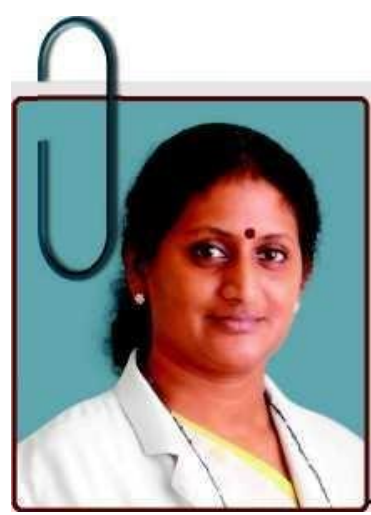

\title{
From the Editors desk.
}

\section{Plagiarism-A Plague in Scientific Research.}

"Stealing from one source is plagiarism, but stealing from many sources is research." To me, this statement seems to undermine the dignity of research. So I thought I should make an attempt to enhance the demarcation line between the two. As I decided to write on plagiarism in scientific writing, I was hit with a tsunami of data from the net. I voraciously read through them and when I thought I was ready, I started to pen down my thoughts. But to my chagrin I realized that I was shuttling back and forth my sentences desperately, to avoid the use of the same words and styles of the other writings. It was quite an unsettling experience. Especially, after being threatened by so many articles, that plagiarism is a big crime, I was even more conscious of not committing one. For once I realized that ignorance is indeed bliss!

But how could I possibly write something very original about plagiarism; something which I did not invent; about which I learnt only from the others? Some of the references were impressive and some of them inspirational. Good information tend to permeate me so much that they start growing outwards as my own ideas. It is, of course, easy to be carried away by them, to end up in an unintentional plagiarism! So how do I write about it, without stealing the words from others and at the same time without missing out all details? As the question grew within me, I realized the enormity of the challenge all scientific writers face. As most of the scientific writings are not entirely original, barring the genre of Einsteins', every researcher/ academician would have lingered at this brink of disaster at least for a while and.. .if they have not done so, they are not researchers; more so, not teachers!

Then I remembered the advice I usually give my undergraduate students on how to write their answers or projects with a touch of originality and individuality; the creativity that has been erased in them by ruthless schooling. Thus I finalised that sharing this advice with my fellow scientific writers would be very appropriate here. I also decided that it would be prudent to expend the same facts that many have written on plagiarism, lest I tread on their shoes!

Learning is an art of four steps. Read, Study, Abstract and Apply. When my students are intimidated by the size of a book I tell them to read a small section, as if they read a story book; no attempt should be made to think or memorize. Then the process of studying starts, where the same pages should be revisited, now more slowly and steadily, but determinedly, trying to comprehend the underlying concept. The next process of abstraction is the most crucial one. This is very unique to every individual mind. All that has been learnt should now be re created by the mind, the way it has been perceived, drawing out the full essence to the best of that individual mind's capacity. I suggest the students to try this exercise, by telling a friend about a three hour movie in just three words. It is indeed amazing to hear numerous versions of a one single movie! As the abstraction is done, volumes of text matter will definitely shrink into a capsule that is easy to carry in the mind. The abstraction should now 
be advanced to the ultimate purpose of application, may it be theory or practice or.... even scientific writing.

To apply the above concept in preparing a scientific article, without blundering on plagiarism, I humbly suggest the following steps.

1. Abundant knowledge should be accumulated on the subject by reading, learning and comprehending. Review of literature recorded in reference card is an all time favourite of mine; a reliable source of data of 'who-said-what-and-when.'

2. The first draft of the manuscript should be prepared without picking up any book or journal or even the reference cards, allowing the information to pour out, onto the paper/monitor, uninhibitedly. No need to stop to check the spelling, grammar or the thesaurus. I guarantee that each and every word in this content prepared so, would be solely the authors!

3. Once completed, this draft should now be cross checked for irrelevant/ missing or copied contents, with all the data resources open again. As Sir Issac Newton said that "If I have seen further, it is by standing on the shoulders of the giants", the manuscript should be strengthened with the knowledge from the other authors, by citing them in all the pertaining and well deserving areas.

4. If an editor of a journal can use a soft ware to detect plagiarism and reject an article, even an author can subject the article to the same test of fire before that, in order not to get rejected. My way is to simply cut and paste my own sentence in the google search bar and on one click I will know how close I am to another author and I will do my best to move the furthest away. This way, I ensure that the web information is used wisely, not to copy data, but to prevent copy a data.

Plagiarism in Indian scientific scenario is grave, as there is no governing body to monitor or to penalise theft of the intellectual property. Please visit the websites of Office of Research integrity (ORI) of the United States and United Kingdom based Code of Publication Ethics (COPE) to realize the gravity of this scientific misconduct and how severely it is being viewed by the rest of the world.

Nevertheless, as I always tell my students, we do not need a 'ring master', to be constantly monitored or regulated, on such a discipline that should be present in every scientist by default.

\section{We shall be our own masters, after all, we are all masters of science!}

Dr. Carounanidy Usha

E mail: jsdigids@gmail.com

Mobile: 9843184039 
